\title{
Investing in soils
}

\author{
The world's soils are under pressure from climate change and population growth. Investors' interest is \\ surging, but scientists have yet to pay soils due tribute.
}

Soil is one of the most precious resources on the planet. Terrestrial vegetation is supported by the water and nutrients that are stored in soils. Key elements such as carbon, nitrogen and phosphorus essential for the functioning of life - are recycled by the myriad of organisms that live within soils. And the organic matter bound up in soils constitutes a significant portion of the world's carbon.

Soil is also an increasingly soughtafter possession. As the global population grows, the amount of arable soil available to each person is set to decline, with potentially negative consequences for global food production. Governments that are concerned about their citizens' future food security, and private investors with an eye for profit, are buying up thousands of hectares of arable land, primarily in the developing world, with the aim of converting it into cropland or pasture.

Apart from the ethical issues associated with the appropriation of land in countries that may need it to support their own burgeoning populations, using land for agriculture comes at significant cost to the structure and functioning of the soil. Nutrients are cycled very differently on farmlands, and the composition of species that live within the soil is altogether changed on conversion to agricultural land. But the precise impact of land use on soil biodiversity, element cycling and the ability of the soils to support life is one of the gaping holes in our understanding of soils. In this focus issue we have gathered together articles - ranging from primary research to opinion pieces - that explore the sensitivity of soils to climate and land-use change, and that highlight the key role that soils play in shaping both the environment and human society.

Agricultural soils are highly susceptible to erosion. Vast quantities of nutrients and carbon (Progress Article, page 311) are lost from agricultural lands to erosion each year, jeopardizing soil fertility and food production. In tropical Africa, decades of farming without adequate fertilizer have drastically limited the amount of food that can be produced (Commentary, page 299). Alarmingly, it is only in the last decade that agencies involved in development have realized that soil fertility needs to be replenished if crop yields are to rise.

Changes in land use, together with climate warming, also influence the biodiversity of soils (Commentary, page 297). The precise consequences for belowground organisms and ecosystem functions such as decomposition have yet to be determined. But the impact could be severe, given that soil biota are central to the biogeochemical cycling of elements. Indeed, the physiology of soil microbes - which is largely overlooked in climate models - could prove to be a key determinant of soil carbon emissions in a warmer world (Letter, page 336, and News \& Views, page 303). If soil microbes become less efficient at higher temperatures, carbon emissions could subside in the long term. But if microbes manage to adapt to a warmer climate, for instance by up-regulating enzyme activity, emissions could intensify. Sorting through these opposing effects is not going to be straightforward. But we cannot afford to ignore such a significant uncertainty.

Given its importance, we know remarkably little about the ways in which human activities are affecting soils. One important obstacle to a better understanding is the huge spatial heterogeneity in the physical make up, biodiversity and function of soils, and hence in their response to disturbance. But a concerted effort to bring soil science to the focus of collaborations between researchers from related disciplines in the biological, geological and sociological sciences should help.

The structure and function of soils has always been subject to change, at least since humans began to farm the land. But owing to dual pressures from climate warming and an increasing population density, the rate of transformation is accelerating. The consequences for the health and stability of ecosystems, sustainability of food production and society (Books \& Arts, page 301) could be extreme. We urgently need a much betterunderstanding of the sensitivity of soils to trends in climate and land use. Much more is at stake than the security of government and private investments in arable land.

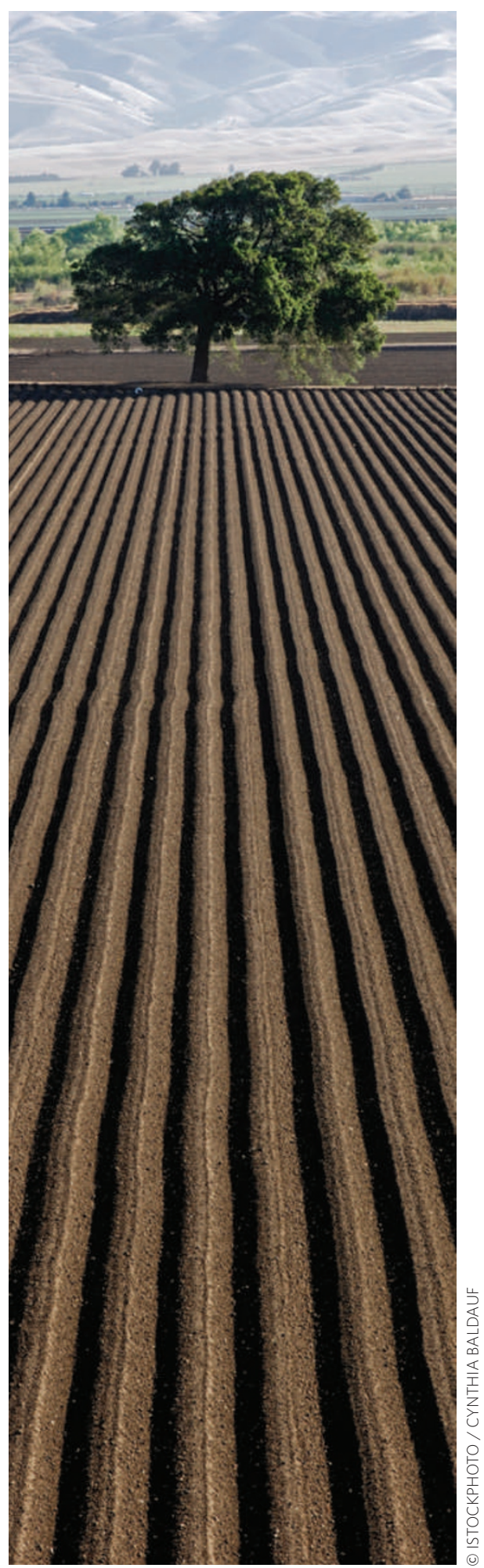

